\title{
АКТУАЛЬНЫЕ ВОПРОСЫ ФУНКЦИОНИРОВАНИЯ ФЕДЕРАЛЬНЫХ ОРГАНОВ ИСПОЛНИТЕЛЬНОЙ ВЛАСТИ В РОССИЙСКОЙ ФЕДЕРАЦИИ
}

\begin{abstract}
Аннотация. В качестве предмета исследования выступают актуальные особенности административно-правового регулирования системы и структуры федеральных органов исполнительной власти, взаимодействия Президента и Правительства Российской Федерации. В статье проанализированы тенденции реформирования федеральных органов исполнительной власти, в частности, создание территориальных министерств, воссоздание государственных комитетов, оптимизация структуры феедеральных органов исполнительной власти путём укрупнения, а также передачи их функции государственным корпорациям. Особый акцент в статье сделан на необходимости законодательного закрепления системы и структуры федеральных органов исполнительной власти. При проведении исследования использовались формально-юридический, структурно-фуннкциональный и исторический методы, которые позволили обеспечить комплексное изучение тенденций развития системы и структуры федеральных органов исполнительной власти. Результатом исследования стали сформулированные особенности функционирования Правительства Российской Федерации, в частности, воссоздание Президиума Правительства Российской Федерации, уникальное совмещение должностей заместителя Председателя Правительства и полномочного представителя Президента, наличие в составе Правительства министров "двойного подчинения» и министров "без портфеля». С точки зрения трёхвидовой системы федеральных органов исполнительной власти проанализирована тенденция к пересмотрю результатов административной реформы в части наделения органов исполнительной власти несвойственными им функциями.
\end{abstract}

Ключевые слова: Президент, Правительство, органы исполнительной власти, административная реформа, территориальные министерства, федеральные министерства, федеральные агентства, федеральные службы, государственное управление, федеральные органы власти.

Review. The study considers the existing peculiarities of legal regulation of the system and structure of federal executive authorities, and interaction of the President and the Government of the Russian Federation. The article analyzes the trends of reforming of federal executive authorities, in particular, the creation of territorial ministries, reconstruction of state committees, optimization of the structure of federal bodies of executive power by means of consolidation and transmission of their functions to the state corporations. Particular emphasis in the article is made on the necessity of legislative regulation of the system and structure of federal executive authorities.The study uses the legal, structural, functional, and historical methods, which provide a comprehensive analysis of trends of the system and structure of federal executive authorities development.As the result of the study the following peculiarities of the Russian Government are formulated: the reconstruction of the Government Presidium, a unique combination of posts of a Deputy Prime Minister and a Presidential Envoy, the presence of Ministers of "dual subordination» and ministers "without portfolio» in the Government. The article also analyzes the tendency of revision of the administrative reform results by providing the executive bodies of the tripartite system with some non-core functions.

Keywords: federal agencies, federal ministries, territorial ministries, administrative reform, executive authorities, Government, President, federal services, public administration, federal authorities.

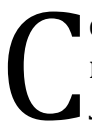
овременная структура органов исполнительной власти в Российской Федерации пережила за последние более чем 20 лет значительные изменения и трансформации, и, казалось бы, обрела на данном этапе свою завершённую форму. Однако такая позиция представляется ошибочной, поскольку различные элементы именно исполнительной власти находятся в постоянной дина- мике, пытаясь найти адекватный ответ вызовам, которые в целом стоят перед механизмом государственного управления.

Исполнительная власть в Российской Федерации, вобрав в себя передовой мировой опыт организации, за прошедшие годы приобрела достаточно много особенностей, обусловленных переходным периодом в становлении новой России, 
влиянием федеративного устройства, вхождением в состав России Крыма, воздействием мировых финансово-экономических кризисов, а также зарубежной санкционной политикой.

Особую роль в механизме управления исполнительной властью играет Президент Российской Федерации, который, формально-юридически не относясь ни к одной ветви власти, обладает значительным объёмом полномочий по отношению к каждой из них. При этом самый большой объём полномочий Президента Российской Федерации как раз приходится на исполнительную ветвь власти. Правовые основы взаимодействия Президента Российской Федерации и органов исполнительной власти закреплены в гл. IV и VI Конституции Российской Федерации, а также в № 2-ФКЗ «О Правительстве Российской Федерации», в частности в гл. V конкретизировано право Президента председательствовать на заседаниях Правительства и его Президиума, урегулированы особенности руководства Президентом некоторыми федеральными органами исполнительной власти (в основном «силового блока»), вопросы отмены Президентом актов Правительства, временного исполнения Председателем Правительства обязанностей Президента, отставки Правительства и сложения им своих полномочий.

Президент Российской Федерации формирует Правительство Российской Федерации и единственное ограничение в этой части - это необходимость согласования кандидатуры председателя правительства Государственной Думой, далее все члены Правительства назначаются на усмотрение Президента Российской Федерации, хотя Конституцией Российской Федерации и предусмотрена обязанность Председателя Правительства Российской Федерации представлять кандидатуры своих заместителей и федеральных министров, а также предложения о системе и структуре федеральных органов исполнительной власти.

Особенностью организации высших органов государственной власти Российской Федерации стало возникновение так называемого правящего «тандема» (в некоторых источниках - российский дуумвират [1]; бинарная модель политического лидерства [2]) - особого политического и функционального взаимодействия Президента и Председателя Правительства Российской Федерации (В.В.Путин - Д.А. Медведев), заключающегося в поочерёдном взаимном назначении на высшие государственные должности и совместном принятии важнейших политических решений, обеспечении их реализации, а также контроля за их исполнением. Возникновение такого «тандема» имеет не только политические, но и правовые предпосылки, обусловленные тем, что ст. 81 Конституции Российской Федерации предусматривает возможность замещения поста Президента одним и тем же лицом в течение только двух сроков подряд (слово «подряд» оказалось ключевым, поскольку, например, в США в отношении Президента речь идёт о двух сроках вообще).

Помимо конституционно предусмотренных механизмов воздействия Президента Российской Федерации на Правительство в практике государственного управления появились и новые формы взаимодействия. Так, п. «б» ст. 83 предусматривает право Президента председательствовать на заседаниях Правительства. Однако, Президент пользуется этим правом, скорее, в исключительных случаях, а в регулярном режиме проводит совещания с членами Правительства, на которых присутствуют обычно Председатель и все его заместители, а также федеральные министры - в зависимости от тематики проводимого совещания. Совещания Президента с членами Правительства стали регулярно проводиться в контексте президентского контроля за исполнением серии «майских» указов 2012 г. Указанные совещания по внешней форме напоминают заседания Президиума Правительства «усечённого» состава Правительства, созданного для решения оперативных вопросов [3]; на протяжении 2000-2008 гг. Президиум Правительства не формировался, практика его проведения была восстановлена с 2008 с назначением В.В. Путина Председателем Правительства. Однако с точки зрения своей конституционно-правовой и административно-правовой сущности, юридического значения принимаемых решений совещания с членами Правительства и заседания Правительства под председательством Президента отличаются принципиально.

Ещё одной особенностью функционирования Правительства и его взаимодействия с Президентом Российской Федерации стала практика уникального совмещения должностей государственной гражданской службы Администрации Президента Российской Федерации и государственных должностей в составе Правительства Российской Федерации. Так, на данный момент такое совмещение должностей происходит в отношении Заместителя Председателя Правительства - Полномочного Представителя Президента в Дальневосточном федеральном округе. Такое 
совмещение должностей приводит, как минимум, двум административно-правовым коллизиям. Вопервых, должности членов Правительства являются государственными должностями [4], т.е. учреждёнными для непосредственного исполнения полномочий, в то же время должности государственной службы учреждаются для обеспечения исполнения полномочий [5] в том числе лиц, замещающих государственные должности. Во-вторых, в Российской Федерации Президент формально не относится ни к одной ветви власти, равно как и обеспечивающий его деятельность государственный орган - Администрация Президента, а при указанном смешении должностей государственной служащий Администрации Президента является одновременно одним из руководителей высшего коллегиального органа уже исполнительной власти - Правительства Российской Федерации. Аналогично совмещал должности в Администрации Президента и Правительстве Российской Федерации в период 2010-2014 гг. А.Г. Хлопонин, который выполнял функции Заместителя Председателя Правительства - полномочного представителя Президента в Северо-Кавказском федеральном округе. Но подобные совмещения должностей в то же время продиктованы особыми условиями осуществления государственного управления в указанных федеральных округах, требующих более высокую степень концентрации властных полномочий [6].

Одна из ключевых особенностей административно-правового обеспечения деятельности федеральных органов исполнительной власти в Российской Федерации заключается в том, что уже на протяжении более 20 лет так и не был принят федеральный закон «Об органах исполнительной власти Российской Федерации», а их система и структура определяется подзаконными нормативными правовыми актами Президента Российской Федерации. Необходимость законодательного регулирования системы и структуры федеральных органов исполнительной власти с правовой точки зрения определяется рядом обстоятельств. Вопервых, п. «г» ст. 71 Конституции относит вопросы установления системы федеральных органов исполнительной власти, порядка её организации и деятельности к исключительному ведению Российской Федерации, а по предметам исключительного ведения Российской Федерации в соответствии со ст. 76 Конституции принимаются федеральные законы. Во-вторых, Конституция Российской Федерации напрямую не предусматривает полномочия
Президента по определению системы и структуры федеральных органов исполнительной власти; ст. 112 Конституции только указывает на обязанность Председателя Правительства Российской Федерации не позднее недельного срока после назначения представить Президенту предложения о структуре федеральных органов исполнительной власти. В-третьих, постановление Конституционного Суда от 27 января 1999 г. № 2-П «По делу о толковании статей 71 (пункт «г»), 76 (часть 1) и 112 (часть 1) Конституции Российской Федерации» [7] установлено, что система федеральных органов исполнительной власти должна определяться законодательно, но ввиду отсутствия такого закона, Президент может издавать указы по вопросам, не урегулированным законодателем. В-четвертых, в последней редакции ст. 32 Федерального конституционного закона от 17 декабря 1997 г. № $2 Ф К 3 ~ « 0$ Правительстве Российской Федерации» установлено, что Президент Российской Федерации «в случае изменения в установленном порядке системы и структуры федеральных органов исполнительной власти до принятия федеральных законов о внесении соответствующих изменений в федеральные законы может перераспределять установленные федеральными законами функции федеральных органов исполнительной власти, деятельностью которых руководит Президент Российской Федерации», т.е. федеральный конституционный закон не исключает, а скорее подтверждает, необходимость принятия федерального закона об органах исполнительной власти.

В составе Правительства Российской Федерации также можно выделить некоторые особенности. Так, по изначальной задумке административной реформы, закреплённой в самой первой редакции Указа Президента от 9 марта 2004 г. № 314 «0 системе и структуре федеральных органов исполнительной власти», у Председателя Правительства должен был быть только один заместитель (п. 8), а, например, руководство аппаратом правительства должно было осуществляться министром «без портфеля» (п. 9). Данная модель организации высшего коллегиального органа исполнительной власти создавалась таким образом, чтобы повысить персональную ответственность и значение федеральных министров. Но со временем количество заместителей Председателя Правительства постепенно увеличивалось: 2004 г. - 1, 2005 г. - 3, 2007 г. - 5, 2008 - 8. Таким образом, каждый из заместителей Председателя Правительства начал курировать определённый блок вопросов 
государственного управления и, соответственно, федеральных органов исполнительной власти.

Ещё одна особенность функционирования Правительства Российской Федерации заключается в наличии в его составе министров «двойного подчинения», подчиняющихся с одной стороны Председателю Правительства, т.к. он возглавляет Правительство, определяет основные направления его работы, в том числе распределяет обязанности между членами Правительства (ст. 24 № 2-ФКЗ от 17.12.1997 г.), с другой стороны Президенту Российской Федерации, поскольку в соответствии со ст. 321997 г. № 2-ФКЗ Президент осуществляет руководство «силовым» блоком федеральных органов исполнительной власти, и руководит входящими в него органами как непосредственно, так и через федеральных министров.

Также обращают на себя внимание полномочия Председателя Правительства в части кадровых решений. Так, Председатель Правительства Российской Федерации может только представлять свои предложения Президенту в процессе формирования состава Правительства Российской Федерации, а также предложения об освобождении от должности членов Правительства, но не имеет права самостоятельно принимать решение об освобождении от должности членов Правительства, т.е. неся всю полноту ответственности за функционирование Правительства, его Председатель не обладает возможностью принимать кадровые решения, даже в отношении федеральных министров «социально-экономического» блока. В дополнение к этому тезису также необходимо отметить, что с точки зрения механизма сдержек и противовесов при взаимодействии исполнительной и законодательной власти Государственная Дума напрямую не может изменить состав Правительства после его формирования, т.е. Государственная Дума может выразить недоверие или отказать в доверии Правительству Российской Федерации, вызвать любого члена Правительства для заслушивания отчёта, но только Президент Российской Федерации может отправить в отставку Правительство или его отдельного члена.

С точки зрения состава Правительства также необходимо выделить входящих в его состав федеральных министров «без портфеля»- членов Правительства, не осуществляющих руководство федеральным министерством, но при этом имеющих право голоса на заседаниях Правительства. Зачастую задача министра «без портфеля» заключается в усилении координационной функции различных органов государственной власти [8]. На данный момент в составе Правительства учреждена должность федерального министра, которую с 2012 г. замещает М.А. Абызов, координируя деятельность «открытого правительства», целью которого является повышение транспарентности федеральных органов исполнительной власти, а также привлечение экспертного сообщества к активному участию в обсуждении планов ключевых государственных реформ и преобразований. Ранее до 2007 г. в составе Правительства учреждалась должность министра Российской Федерации - руководителя Аппарата Правительства, по форме также министра «без портфеля», но, необходимо отметить, что Аппарат Правительства является самостоятельным государственным органом с предельной численностью работников более 1400 единиц, т.е. больше чем центральные аппараты подавляющего числа федеральных органов исполнительной власти.

Очень интересным представляется сопоставление количества федеральных органов исполнительной власти на этапе становления новой российской государственности и на современном этапе. Так, в соответствии с Указом Президента Российской Федерации от 14 августа 1996 г. № 1177 «0 структуре федеральных органов исполнительной власти» действовали - 24 министерства, 19 государственных комитетов, 18 федеральных служб, 3 российских агентства, 2 федеральных надзора - всего 67 федеральных органов исполнительной власти, включая Правительство. На данный момент в соответствии с Указом Президента Российской Федерации от 21 мая 2012 года № 636 «0 структуре федеральных органов исполнительной власти» действуют - 21 федеральное министерство, 31 федеральная служба, 23 федеральных агентства - всего 76 федеральных органов исполнительной власти, причём их количество в последнее время уменьшилось в контексте оптимизации системы государственного управления в условиях сложной финансово-экономической ситуации (были упразднены Федеральная служба по тарифам (21.05.2015 г.); Министерство по делам Крыма (15.07.2015 г.); Федеральная служба по оборонному заказу (1.01.2015 г.); Рособоронпоставка (1.01.2015 г.); Министерство регионального развития (8.09.2014 г.)).

Интересной также представляется динамика количества федеральных министерств: если в 1996 г. и в 2015 г. их было 24 и 21, соответственно, то в первой редакции упомянутого выше Указа 2004 г. 
№ 314 - федеральных министерств было всего 14 ( 5 в «силовом» блоке и 9 в «социально-экономическом» блоке), таким образом именно в контексте административной реформы 2004 году была претворена в жизнь серьёзная попытка оптимизации аппарата управления, однако складывающиеся впоследствии условия государственного управления привели к дальнейшему увеличению как количества федеральных министерств, в частности, так и общего числа федеральных органов исполнительной власти.

Одной из целей преобразования системы федеральных органов исполнительной власти было чёткое распределение функций по выработке государственной политики и нормативному правовому регулированию, предоставлению государственных услуг, а также государственному контролю и надзору, соответственно, между федеральными министерствами, агентствами и службами. Однако с принятием Указа Президента Российской Федерации «Вопросы структуры федеральных органов исполнительной власти» от 24 сентября 2007 г. № 1274 такая трёхвидовая система была нарушена: п. 4 предусматривал создание государственных комитетов - типа федеральных органов исполнительной власти, который мог совмещать в себе все вышеозначенные функции, и таким образом нарушал логику, положенную в основу преобразований системы федеральных органов исполнительной власти. В форме государственных комитетов были образованы в 2007 году Росрыболовство и Росмолодёжь [9], которые, однако, были преобразованы в федеральные агентства уже через незначительный промежуток времени с принятием Указа Президента Российской Федерации «Вопросы системы и структуры федеральных органов исполнительной власти» от 12 мая 2008 г. № 724.

В целом визуальная «правовая стройность» трёхвидовой системы была восстановлена, но при детальном изучении полномочий федеральных органов исполнительной власти обнаруживаются многочисленные факты наделения министерств, агентств и служб несвойственными им по задумке административной реформы функциями. В качестве примеров можно назвать, ФСБ России и ФТС России, которые наделены функциями по нормативному правовому регулированию в установленной сфере деятельности; МЧС России и МВД России осуществляют государственный контроль, а, например, Росгидромет (федеральная служба) осуществляет функции по предоставлению государственных услуг.
Также упомянутое объединение функций различных типов органов исполнительной власти происходило в контексте упразднения федеральных агентств и федеральных служб и возврата их полномочий в федеральные министерства. Примерами таких упразднений с возвращением функции по предоставлению государственных услуг могут служить упразднённые в 2010 году Федеральное агентство по науке и инновациям и Федеральное агентство по образованию [10], функции которых были переданы в Минобранауки России; а в части передачи функций по государственному контролю и надзору - упразднение Федеральной службы по надзору за соблюдением законодательства в области охраны культурного наследия (Росохранкультура) и передаче её функций Министерству культуры [11].

Ещё одной из тенденций последнего времени в преобразованиях федеральных органов исполнительной власти стало их укрупнение. Так, в соответствии с Указом Президента Российской Федерации «0 некоторых вопросах государственного управления в сфере антимонопольного и тарифного регулирования» от 21 июля 2015 года № 373 была упразднена Федеральная служба по тарифам и её полномочия были переданы Федеральной антимонопольной службе. С предложением таких преобразований выступил Председатель Правительства Д.А. Медведев, обосновав свою позицию близостью задач указанных органов, необходимостью экономии бюджетных средств, обеспечением лучшего взаимодействия в процессе государственного управления, снятием противоречий при деятельности близких по сфере органов власти, а также тем обстоятельством, что ФСТ России и ФСТ России уже были когда-то единым органом [12]. Особое внимание при проведении подобных преобразований обращается на обеспечение правопреемства при проведении ликвидационных мероприятий, обеспечение непрерывности осуществления передаваемых функций, сохранение кадрового потенциала упраздняемого органа, а также приведение в соответствие нормативной правовой базы объединённого органа исполнительной власти.

Значительное увеличение количества федеральных министерств произошло в контексте их создания по территориальному принципу - Минкавказ, Минвостокразвития и Минкрым - это ещё одна из тенденций в развитии структуры органов исполнительной власти. Указанные министерства создавались для концентрации ресурсов государственного управления с целью развития отдельных групп регионов России. По сути территориаль- 
ному министерскому управления были подчинены 3 из 9 созданных в 2000 году федеральных округов. Однако наличие таких министерств носит, скорее всего, временный характер и предполагается, что после выполнения задачи по достижению определённого уровня социально-экономического развития управляемых в особом порядке территорий, такие министерства будут упразднены. Ярким примером может служить просуществовавшее сравнительного недолго Министерство Российской Федерации по делам Крыма (31.03.2014 г. 15.07.2015 г.), которое было упразднено в связи с исполнением задачи по интеграции Республики Крым в состав Российской Федерации, необходимостью экономии управленческих средств, а также рационализации работы федеральных органов исполнительной власти. При этом, по словам Председателя Правительства Д.А. Медведева, высказанным на уже упомянутом совещании 15 июля 2015 года, два других оставшихся территориальных министерства - Минвостокразвития и Минкавказ - должны продолжить своё существование, т.к. «решают очень большие задачи, рассчитанные на десятилетия», а управляемые ими территории имеют «огромное количество нерешённых проблем: и социальных, и экономических, и даже идеологических, по которым необходимо обеспечивать координацию по линии федеральных структур».

Изменения структуры федеральных органов исполнительной власти также связаны с тенденцией передачи функций от органов исполнительной власти другим государственным органам или даже государственным корпорациям. Примером таких преобразований может служить передача полномочий Федеральной службы по финансовым рынкам Центральному Банку [13], а также упразднение в 2008 г. Федерального агентства по атомной энергии [14] (Росатом) и передача его полномочий Государственной корпорации по атомной энергии «Росатом».

Подводя итоги тенденций развития, а также особенностей функционирования системы и структуры федеральных органов исполнительной власти, можно сделать вывод о том, что для неё характерен достаточно высокий темп изменений и преобразований, происходящих, как ни странно, несмотря на то, что в целом в государстве сохраняется преемственность власти и определённый уровень политической стабильности. Одним из ярких примеров, иллюстрирующих постоянные изменения структуры органов управления в рамках одной сферы, является сфера строительства Минстрой (1994-1997 гг.) - Государственный комитет по жилищной и строительной политике (19971998 гг.) - Министерство Российской Федерации по земельной политике, строительству и жилищно-коммунальному хозяйству (1998-1998 гг.) Государственный комитет Российской Федерации по строительной, архитектурной и жилищной политике (1998-1999 гг.) - Государственный комитет Российской Федерации по строительству и жилищно-коммунальному комплексу (1999-2004 гг.) Федеральное агентство по строительству и жилищно-коммунальному хозяйству (2004-2008 гг.) профильные департаменты Минрегиона (20082012 гг.; кстати, Минрегион - также впоследствии был упразднён в 2014 году) - Федеральное агентство по строительству и жилищно-коммунальному хозяйству (2012-2014 гг.) - Министерство строительства и ЖКХ (2014 г. - по н.в.(?)). Таким образом, изменения в механизме государственного управления важнейшей сферой происходили с периодичностью раз в несколько лет, причём неоднократно происходил возврат к формам организации, которые уже использовались. И это, к сожалению, не единственный пример в структуре федеральных органов исполнительной власти.

Очевидно, что изменения структуры федерального государственного управления не могут происходить в таком темпе, государственное управление должно прежде всего характеризоваться долгосрочными целями и стабильным механизмом их достижения. Таким образом, одним из способов повышения качества преобразований, снижения необоснованно высокого темпа изменений, снижения субъективного фактора, обеспечения последовательного и преемственного реформирования в системе и структуре федеральных органов исполнительной власти должно стать её законодательное закрепление, которое позволит более действенно использовать механизм сдержек и противовесов.

\section{Библиография:}

1. Отрокова О.Ю. Российский дуумвират: причины устойчивости модели соуправления / Известия Академии управления: теория, стратегии, инновации. - 2012.-№ 2. - С. 68-70

2. Лейченко О.Ф. Тандем как особенность политического лидерства в современной России / Гуманитарные исследования в Восточной Сибири и на Дальнем Востоке. - 2010.-№ 4. - С. 90-94 
3. О Правительстве Российской Федерации: Федеральный конституционный закон от 17 декабря 1997 г. № 2-ФКЗ // Собрание законодательства Российской Федерации. - 1997.-№ 51. - Ст. 5712

4. О государственных должностях Российской Федерации : Указ Президента Российской Федерации от 11 января 1995 г. № 31 // Российская газета. - 1995. - № 11-12

5. государственной гражданской службе Российской Федерации : Федеральный закон от 27 июля 2004 г. № 79-Ф3 // Собрание законодательства Российской Федерации. - 2004.-№ 31. - Ст. 3215

6. Черкасов К.В. Институт полномочных представителей Президента Российской Федерации в федеральных округах: характеристика и место в системе государственной власти России / Современное право. - 2007.-№ 5. C. $49-52$

7. По делу о толковании статей 71 (пункт «г»), 76 (часть 1) и 112 (часть 1) Конституции Российской Федерации : постановление Конституционного Суда Российской Федерации от 27 января 1999 г. № 2-П // Собрание законодательства Российской Федерации. - 1999.-№ 6. - Ст. 866

8. Семенова И. Что в портфеле у министра без портфеля? [Электронный ресурс] / Российская газета. - 2002. Режим доступа: http://www.rg.ru/Anons/arc_2002/0821/4.shtm

9. Вопросы структуры федеральных органов исполнительной власти: Указ Президента Российской Федерации от 24 сентября 2007 г. № 1274 // Собрание законодательства Российской Федерации. - 2007.-№ 40. - Ст. 4717

10. Вопросы Министерства образования и науки Российской Федерации : Указ Президента Российской Федерации от 4 марта 2010 г. № 271 // Собрание законодательства Российской Федерации. - 2010.-№ 10. - Ст. 1057

11. Вопросы Министерства культуры Российской Федерации : Указ Президента Российской Федерации от 8 февраля 2011 г. № 155 // Собрание законодательства Российской Федерации. - 2011.-№ 7. - Ст. 938

12. Стенограмма рабочей встречи Председателя Правительства Российской Федерации Д.А. Медведева и Президентом Российской Федерации В.В. Путиным. Московская область. Ново-Огарёво.15 июля 2015 г. [Электронный ресурс] / Официальный сайт Президента Российской Федерации. - 2015. - 15 июля. Режим доступа: http://special. kremlin.ru/events/president/transcripts/49996

13. Об упразднении Федеральной службы по финансовым рынкам, изменении и признании утратившими силу некоторых актов Президента Российской Федерации: Указ Президента Российской Федерации от 25 июля 2013 г. № 645 // Собрание законодательства Российской Федерации. - 2013.-№ 30 (ч. 2). - Ст. 4086

14. О мерах по созданию Государственной корпорации по атомной энергии «Росатом» : Указ Президента Российской Федерации от 20 марта 2008 г. № 369 // Собрание законодательства Российской Федерации. - 2008.-№ 12.Ст. 1112.

15. Ю.А. Тихомиров, Г.А. Василевич Государственное управление и перспективы развития // Журнал зарубежного законодательства и сравнительного правоведения / Journal of foreighn legislation and comparative law. - 2011. 6. - С. $21-25$.

16. Колюх В.В. Дуализм исполнительной власти: конституционные предпосылки и средства ограничения // Право и политика. - 2015. - 6. - С. 759 - 765. DOI: 10.7256/1811-9018.2015.6.15285.

\section{References (transliterated):}

1. Otrokova O.Yu. Rossiiskii duumvirat: prichiny ustoichivosti modeli soupravleniya / Izvestiya Akademii upravleniya: teoriya, strategii, innovatsii. - 2012.-№ 2. - S. 68-70

2. Leichenko O.F. Tandem kak osobennost' politicheskogo liderstva v sovremennoi Rossii / Gumanitarnye issledovaniya v Vostochnoi Sibiri i na Dal'nem Vostoke. - 2010.-№ 4. - S. 90-94

3. O Pravitel'stve Rossiiskoi Federatsii : Federal'nyi konstitutsionnyi zakon ot 17 dekabrya 1997 g. № 2-FKZ // Sobranie zakonodatel'stva Rossiiskoi Federatsii. - 1997.-№ 51. - St. 5712

4. O gosudarstvennykh dolzhnostyakh Rossiiskoi Federatsii : Ukaz Prezidenta Rossiiskoi Federatsii ot 11 yanvarya 1995 g. № 31 // Rossiiskaya gazeta. - 1995. - № 11-12

5. O gosudarstvennoi grazhdanskoi sluzhbe Rossiiskoi Federatsii : Federal'nyi zakon ot 27 iyulya 2004 g. № 79 -FZ // Sobranie zakonodatel'stva Rossiiskoi Federatsii. - 2004.-№ 31. - St. 3215

6. Cherkasov K.V. Institut polnomochnykh predstavitelei Prezidenta Rossiiskoi Federatsii $\mathrm{v}$ federal'nykh okrugakh: kharakteristika i mesto v sisteme gosudarstvennoi vlasti Rossii / Sovremennoe pravo. - 2007.-№ 5. - S. 49-52

7. Po delu o tolkovanii statei 71 (punkt «g»), 76 (chast' 1) i 112 (chast' 1) Konstitutsii Rossiiskoi Federatsii : postanovlenie Konstitutsionnogo Suda Rossiiskoi Federatsii ot 27 yanvarya 1999 g. № 2-P // Sobranie zakonodatel'stva Rossiiskoi Federatsii. - 1999.-№ 6. - St. 866

8. Semenova I. Chto v portfele u ministra bez portfelya? [Elektronnyi resurs] / Rossiiskaya gazeta. - 2002. - Rezhim dostupa: http://www.rg.ru/Anons/arc_2002/0821/4.shtm

9. Voprosy struktury federal'nykh organov ispolnitel'noi vlasti: Ukaz Prezidenta Rossiiskoi Federatsii ot 24 sentyabrya 2007 g. № 1274 // Sobranie zakonodatel'stva Rossiiskoi Federatsii. - 2007.-№ 40. - St. 4717

10. Voprosy Ministerstva obrazovaniya i nauki Rossiiskoi Federatsii : Ukaz Prezidenta Rossiiskoi Federatsii ot 4 marta 2010 g. № 271 // Sobranie zakonodatel'stva Rossiiskoi Federatsii. - 2010.-№ 10. - St. 1057

11. Voprosy Ministerstva kul'tury Rossiiskoi Federatsii : Ukaz Prezidenta Rossiiskoi Federatsii ot 8 fevralya 2011 g. № 155 // Sobranie zakonodatel'stva Rossiiskoi Federatsii. - 2011.-№ 7. - St. 938 
12. Stenogramma rabochei vstrechi Predsedatelya Pravitel'stva Rossiiskoi Federatsii D.A. Medvedeva i Prezidentom Rossiiskoi Federatsii V.V. Putinym. Moskovskaya oblast'. Novo-Ogarevo.15 iyulya 2015 g. [Elektronnyi resurs] / Ofitsial'nyi sait Prezidenta Rossiiskoi Federatsii. - 2015. - 15 iyulya. Rezhim dostupa: http://special.kremlin.ru/events/president/ transcripts/49996

13. Ob uprazdnenii Federal'noi sluzhby po finansovym rynkam, izmenenii i priznanii utrativshimi silu nekotorykh aktov Prezidenta Rossiiskoi Federatsii: Ukaz Prezidenta Rossiiskoi Federatsii ot 25 iyulya 2013 g. № 645 // Sobranie zakonodatel'stva Rossiiskoi Federatsii. - 2013.-№ 30 (ch. 2). - St. 4086

14. O merakh po sozdaniyu Gosudarstvennoi korporatsii po atomnoi energii «Rosatom» : Ukaz Prezidenta Rossiiskoi Federatsii ot 20 marta 2008 g. № 369 // Sobranie zakonodatel'stva Rossiiskoi Federatsii. - 2008.-№ 12.-St. 1112.

15. Yu.A. Tikhomirov, G.A. Vasilevich Gosudarstvennoe upravlenie i perspektivy razvitiya // Zhurnal zarubezhnogo zakonodatel'stva i sravnitel'nogo pravovedeniya / Journal of foreighn legislation and comparative law. - 2011. - 6. C. $21-25$.

16. Kolyukh V.V. Dualizm ispolnitel'noi vlasti: konstitutsionnye predposylki i sredstva ogranicheniya // Pravo i politika. 2015. - 6. - C. 759 - 765. DOI: 10.7256/1811-9018.2015.6.15285. 